\title{
Tema 9. El barrio, la prosocialidad y la solidaridad (competencia ciudadana fundamental)
}

\section{Presentación}

El niño, el barrio y la calle es un tema no muy común en la bibliografía psicológica ni en la jurídica, pero de paso podemos establecer una correlación entre ellos por medio de la categoría de construcción de la identidad social, la prosocialidad y la solidaridad, que parten de un principio imparcial en el que podemos sopesar la calle como aquel espacio donde aparecen modelos sociales aceptados o rechazados.

\section{Propósito (objetivo)}

Reflexionar de forma crítica sobre la relación del niño y de la niña con la calle, el barrio y la ciudad, que a su vez le permita al pedagogo tener una posición frente a los fenómenos o síntomas del vínculo social en que se ve involucrado el niño-sujeto, y en especial la manera como puede orientar a los padres y a los niños sobre conductas prosociales y de solidaridad en su entorno. 


\section{Conceptualización general}

Por lo general se considera que entre el niño y la calle existe una relación peyorativa, pues la calle ha sido el escenario de fenómenos como el gaminismo y el vandalismo, de los cuales algunos menores de edad han sido protagonistas. Sobre ello podemos extraer uno de los párrafos de la guía Problemática social colombiana, del profesor Juan Alejandro Álvarez Cadavid:

La antropóloga Virginia González, al respecto, apunta que uno de los factores que lleva a la expulsión —o autoexpulsión- de un miembro de la familia, generando el fenómeno del gaminismo, es la falta de atención de sus necesidades primarias, convirtiéndose para ese sujeto el medio callejero en su hábitat socializante, operativo y de abrigo; la calle, aparentemente, es un mundo sin fronteras, "abierto" a la carencia de esperanzas y de futuro, situación que indiscutiblemente afecta la convivencia y agudiza la problemática de violencia citadina. (2011, p. 110)

Las acciones, excesos o defectos de alguno de los miembros de la familia (agresión, autoritarismo, alcoholismo, drogadicción, fanatismo, ausencia prolongada o abandono, incumplimiento de las responsabilidades básicas de alimentación, educación, salud y vivienda digna, entre otros) desembocan muchas veces en la salida voluntaria o forzada del niño a la calle; situación que da cuenta de la maltrecha relación del niño con sus vínculos familiares y sociales, produciendo síntomas problemáticos en el lazo social, tan comunes hoy, como por ejemplo:

- El maltrato infantil: cuyas causas suelen situarse en el autoritarismo y en los bajos niveles de tolerancia que son transmitidos mediante actos de violencia intrafamiliar.

- El abuso sexual y la explotación sexual: debido a la inadecuada satisfacción de necesidades básicas, la sustitución de las figuras paternas (Consejería Presidencial para la Política Social y Alcaldía de Medellín, 1997, p. 24), entre otras. 
- La explotación laboral del niño y de la niña: producto de una desarticulación de la responsabilidad de los padres. Las causas de este fenómeno incluyen desde el problema estructural de la economía frente al empleo, hasta la desintegración familiar, que muchas veces desembocan en que los menores se conviertan en cabezas de familia, en su sometimiento a trabajos en la calle, en ventas, con el riesgo de ser utilizados para actividades ilícitas.

- La infracción de la ley y de la norma: que tiene sus orígenes en posiciones irresponsables e inconsistentes, en la ausencia de valores de los mismos referentes paternos, y en el detrimento de su función como límite y ley; en la violencia intrafamiliar, en el desempleo de los padres.

Además, según Gutiérrez:

La exaltación de la agresión provista por los medios (y la cultura misma) promueve en los niños principios y valores violentos como los siguientes:

- Perder el control y volverse agresivo está bien.

- A través de la violencia se pueden lograr objetivos.

- Lesionar o matar a personas que piensan diferente es admisible en algunos casos, etc. (2000, p. 30)

Estas problemáticas vulneran los derechos de los niños, como el derecho a la vida, a la satisfacción de las necesidades básicas, al respeto por la diferencia, al buen trato, a vivir en un ambiente sano y a no trabajar antes de la edad permitida. Asimismo, como respuesta a estas se busca a veces un "chivo expiatorio" y se realizan juicios apresurados e inquisidores frente a los padres, que en realidad, más que aportar a la comprensión y a la solución del problema, agudizan el fenómeno. Por esto, no se trata de señalar la culpabilidad de un actor determinado frente a estas situaciones, que de hecho son multicausales, sino de comprender la lógica del fenómeno multidimensional dentro del sistema de relaciones familiares y culturales, y preguntarse por la historia de los padres o tutores, en procura de poder lograr a corto, mediano 
y largo plazo la implementación de estrategias educativas frente a la problemática de los padres ausentes, es decir, estrategias de motivación, más que de sanción.

En oposición a una mirada negativa, la relación del menor con la calle puede no ser solo peyorativa, y convertirse en un lugar apropiado para la recreación y la lúdica, en un espacio para identificar los fines de la comunidad, siempre que la noción de comunidad y vecindario existan como una práctica de autocuidado entre los miembros del barrio.

En este punto cabe señalar que la calle es y será espacio de modelos esenciales de socialización, entre los cuales, además de los propuestos por el mercado (televisión), la economía, el poder, la religión, están los propuestos por los padres y los educadores, y de los cuales se desprende que el trabajo de estos consiste en proyectar el proceso formativo hacia la calle como espacio de socialización.

Así, la calle no será necesariamente espacio de referentes delincuenciales, los cuales pueden ser otro tipo de identidad, sino que se puede convertir, proyectar y afianzar en un tópico para hacer un despliegue de las habilidades sociales y competencias ciudadanas (de su prosocialidad) de los niños mediante grupos, comités y semilleros comunitarios, de deportes, ambientales, entre otros, gestionados a partir del mismo aporte y cooperación de los padres y los educadores.

En una época en la cual las oportunidades que brinda el desarrollismo económico son cada vez menos accesibles para la satisfacción de las necesidades biopsicosociales, aparecen los fenómenos de la delincuencia en los barrios como modelos para los niños. Para nadie es un secreto que hay niños que toman como ideal a ciertos actores armados del barrio o de la nación, que se ven involucrados a partir de duelos no elaborados, a causa de la muerte violenta de familiares, vecinos o amigos, e incluso de otros niños, contribuyendo esto a nódulos de resentimiento individual que inevitablemente tienen efectos en el vínculo social.

En este sentido, la calle como espacio de socialización implica propuestas de identificación aceptables e inaceptables, o deseables e indeseables, las cuales a pesar del reproche moral, cumplen una función identitaria en los procesos de construcción de personalidad de los niños. A través de cualquiera de ellas, se vincula el deseo del niño-sujeto, 
produciendo efectos de identificación y de configuración de lugares que le permiten establecer construcciones sobre su ser (principios, poder, reconocimiento). Ellas se transforman en prédicas o relatos de su propia vida, con un lugar dentro del vínculo social.

Ante dicha situación es importante tener en cuenta que existe, además de las requeridas exigencias para la protección física del menor, unas exigencias para la protección psíquica del menor, entre ellas: el diálogo y la escucha activa.

\section{Prosocialidad y solidaridad en el desarrollo infantil}

La conducta prosocial es definida por múltiples autores, entre ellos por Garaigordobil y Fagoaga (2006), quienes la entienden como "toda conducta social positiva con o sin motivación altruista” (p. 65). Esto quiere decir que se trata de una conducta que fomenta el cuidado y el respeto por el otro, que no daña y es asertiva.

La conducta prosocial refuerza la autogratificación del buen obrar y del buen decir. En especial, con esta se busca favorecer a los otros sin pretender para uno un beneficio propio, excepto el de reconocer que se ha hecho lo correcto. Cuando se habla de conducta prosocial positiva se entiende esta como aquella que no daña, que no es agresiva.

Algunas conductas prosociales fundamentales son:

- La empatía, como la práctica de ponerse emocionalmente en el lugar del otro, en una situación que responde a la pregunta sobre cómo me sentiría en esa situación. Se busca evitar emitir un juicio sobre lo que ha hecho el otro o una valoración sin antes ponerse en su lugar.

- La toma de perspectiva, vinculada a la anterior, es el ejercicio y práctica de tratar de pensar como el otro, de acuerdo con los recursos cognitivos del otro, el estilo de vida que ha llevado y su personalidad. Se responde así a cómo reaccionaría el otro ante una situación. De esta manera se aprende a contrastar y diferenciar la perspectiva del otro frente a la propia, base del respeto a la diferencia. 
- La solidaridad o conducta de ayuda, entendida como toda acción realizada para mejorar la situación de otra persona o ser vivo, con la cual se busca aprehender la compasión y producir bienestar. Es la base del aprendizaje del trabajo en grupo y del trabajo en equipo.

Si no se garantizan los derechos básicos del niño ni su protección psíquica, si no se cuida del goce efectivo de estos, el niño se desenvuelve en un ambiente de frustración y con ello es casi inviable que se dé la formación de conductas prosociales. Si el Estado, la sociedad y la familia no respetan y protegen la alteridad y el desarrollo del niño, este aprenderá socialmente que si no tiene las mínimas garantías para vivir, los otros tampoco las tienen o no se las debe a nadie. En tales circunstancias no podrá ser empático, tener perspectiva ni ser solidario, recurrirá siempre al pensamiento egocéntrico para sobrevivir, defenderse y asegurarse lo mínimo para sí.

\section{Acercamiento personal (reflexión)}

- ¿Qué puede hacer el educador ante las situaciones de violencia en el barrio que afectan a los alumnos o lo afectan a él mismo?

- ¿En cuanto a la protección psíquica, además de la escucha, qué otras actividades o acciones cree que podrían servir para cuidar a los niños de entornos barriales violentos?

- ¿Es usted compasivo consigo mismo o es duro y se trata mal? $¿$ Cree que puede enseñar la solidaridad y la compasión a sus hijos y a otros niños?

- ¿Qué buenas practicas comunitarias y culturales puede destacar para que los niños puedan experimentar la calle y el barrio como un espacio de formación ciudadana? Describa prácticas de solidaridad y cuidado de los vecinos, los habitantes, los animales y el medio ambiente. 


\section{Actividades sugeridas}

Búsquedas en Internet y bibliotecas

Búsquedas de casos en prensa

Preguntas para debates grupales
- Explore en las redes sociales distintas conductas prosociales y diferéncielas de otras conductas compasivas.

- Encuentre situaciones en las cuales los animales les enseñan a los humanos a ser compasivos.

- Profundice en los conceptos de empatía, toma de perspectiva y solidaridad, realizando una búsqueda y reflexionando en torno a casos documentados de niños que han vivido en la calle y de niños que han sobresalido por su liderazgo.

- Construya un fichero de conductas prosociales que puede enseñar a los niños en la casa y en la escuela, y explique cómo se puede lograr que estas se implementen como acciones autogratificantes y no impuestas.

- Los mencionados síntomas del lazo social en el niño tienen relación directa con los temas 1 y 2 trabajados en este manual; repasen los conceptos centrales y elaboren un ensayo de dos páginas sobre la relación de estos síntomas con la función paternal y maternal, la identificación, la heteronomía y el modelamiento de aprendizajes.

- Después de las consultas realizadas, establezcan por medio de un debate grupal qué hace o qué es lo que más incide en la elección de un niño para que este se identifique con un modelo particular, tanto aceptado como rechazado socialmente. 


\section{Bibliografía básica}

Acevedo, O. y Suremain, M. (2000). La paternidad en busca de un habla propia: Esquemas y representaciones sobre la paternidad en padres varones de sectores populares de la ciudad de Medellín. En Masculinidades en Colombia: Reflexiones y perspectivas (pp. 91-99). Bogotá: AVsC Internacional.

Acevedo, O. (2017). A mí me educó un árbol: Psicagogía del amor. Bogotá: Comisión de Conciliación Nacional.

Acevedo, O. y Mesa, O. (2003). Manual: Prevención temprana de la agresión en la escuela. Medellín: Editorial Universidad de Antioquia y Secretaría de Educación de Medellín.

Alvarado, K. (2012). Empatía y clima familiar en niños y niñas costarricenses de edad escolar. Actualidades Investigativas en Educación, 12(3) 1-27.

Anónimo (1983). Lazarillo de Tormes. Bogotá: La Oveja Negra.

Arce, S., Cordera, M. y Perticarari, M. (2012). La construcción de conductas prosociales en niños y adolescentes de la ciudad de Córdoba. Anuario de Investigaciones de la Facultad de Psicología, 1(1), 68-82.

Arenas, M. y Parra, E. (2005). Habilidades mentalistas y conducta prosocial en niños de edad escolar con característica de deprivación social (tesis inédita de maestría). Pontificia Universidad Javeriana, Bogotá, Colombia.

Aristóteles (1982). Ética a Nicómaco. Ciudad de México: Porrúa.

Asamblea General de las Naciones Unidas (1985). Resolución 40/34/29 de 1985. Recuperado de https://is.gd/RRWxAJ

Auné, S., Blum, D., Abal, J., Lozzia, G. y Attorresi, H. (2014). La conducta prosocial: Estado actual de la investigación. Perspectivas en Psicología, 11(2), 21-33.

Berenstein, A. (1981). Psicodinámica de la delincuencia juvenil. Barcelona: Paidós.

Bettelheim, B. (1982). Educación y vida moderna, un enfoque psicoanalítico. Barcelona: Grijalbo.

Caicedo, J. (2014). Fortalecimiento de las conductas prosociales en los niños y niñas de la Institución Educativa Técnico-Industrial Julio Flores, sede Mariscal Sucre y Olga Forero de la ciudad de Chiquinquirá, Boyacá 
(tesis inédita de pregrado). Universidad Nacional Abierta y a Distancia, Tunja, Colombia.

Camacho, E. (2012). Interacciones sociales en contingencias de cooperación y competencia: ¿Comportamiento suplementario o sustitutivo? Revista mexicana de análisis de la conducta, 38(2), 22-38.

Colombia es el $4 .^{\circ}$ país del mundo donde se asesinan más niños y niñas, según nuestro informe: En deuda con la niñez (31 de mayo de 2017). Save the Children. Recuperado de https://is.gd/h0YUGO

Corte Penal Internacional (17 de julio de 1998). Estatuto de la Corte Penal Internacional adoptado por la Conferencia diplomática de plenipotenciarios de las Naciones Unidas. Roma, Italia. Entrada en vigor para Colombia el 1 de noviembre de 2002, en virtud de la Ley 472 de 2002.

Damasio, A. (2000). Sentir lo que sucede. Santiago de Chile: Andrés Bello.

Defensoría del Pueblo y Unicef (2006). Caracterización de las niñas, niños $y$ adolescentes desvinculados de los grupos armados ilegales: Inserción social y productiva desde un enfoque de derechos humanos. Bogotá: Defensoría del Pueblo y Unicef.

Dickens, C. (1982). Oliver Twist, Ciudad de México: Porrúa.

Domínguez, E. (2003). Leydi Tabares, la niña que vendía rosas. Bogotá: Intermedio Editores.

Espinoza, B. (1980). La ética demostrada según el orden geométrico. Madrid: Orbis.

García, E. (2003). Consideraciones políticas para el manejo de los niños infractores en América Latina. En C. Tejeiro (coord.), Niñez y conflicto armado: Desde la desmovilización hacia la garantía integral de derechos de infancia. Bogotá: Universidad de los Andes.

Gobierno analizará endurecimiento de penas a menores (5 de agosto de 2013). El Tiempo, s. p.

González, G. (2002). Los niños de la guerra. Bogotá: Planeta.

Groening, M. (1993). Bart Simpson: Guía para la vida. Barcelona: Bruguera. Instituto Colombiano de Bienestar Familiar (2013). Observar para proteger: Enfoques alternativos para valorar la dinámica y el riesgo de reclutamiento y utilización de niños, niñas y adolescentes por grupos armados organizados al margen de la ley (GAOML) en Colombia. Bogotá: Instituto Colombiano de Bienestar Familiar. Recuperado de https://is.gd/5DhxEt 
Jiménez, A. (2013). Infancia: Ruptura y discontinuidades de su historia en Colombia. Bogotá: Ecoe Ediciones.

Jiménez, A., Bonilla, M., Arévalo, L. y Sandoval, N. (2009). El delito invisible: Criterios para la investigación del delito de reclutamiento ilícito de niños y niñas en Colombia. Bogotá: Coalición contra la Vinculación de Niños, Niñas y Jóvenes al Conflicto Armado en Colombia y Comisión Colombiana de Juristas. Recuperado de https://is.gd/UrRhW6

Las cifras sobre los niños y la guerra (8 de junio de 2016). El Espectador, recuperado de https://is.gd/luyGfw

Ley 1098 de 2006 ( 8 de noviembre de 2006), por la cual se expide el Código de la Infancia y la Adolescencia. Diario Oficial n. ${ }^{\circ} 46446$. Recuperado de https://is.gd/FahCAk

Lozano, P. (2005). La guerra no es un juego de niños: Historias de una infancia quebrada por el conflicto. Bogotá: Intermedio Editores.

Maffesoli, M. (1990). El tiempo de las tribus. Barcelona: Icaria.

Mahecha, J. y Rojas, A. (8 de julio de 2012). Relato de una "pisa suave". El Espectador, recuperado de https://is.gd/LcVdHy

Marín, J. (2009). Conductas prosociales en el barrio Los Pinos de la ciudad de Barranquilla, Colombia. Revista CEs Psicología, 2(2), 60-75.

Organización Internacional para las Migraciones y Procuraduría General de la Nación (2007). ¿Judicialización de niños, niñas y adolescentes desvinculados del conflicto armado? Niños en la guerra: protegiendo y restituyendo sus derechos. Bogotá: Organización Internacional para las Migraciones y Procuraduría General de la Nación.

Ossa, C. (2015) Diálogos sentipensantes sobre patriarcado, masculinidades y guerra en Medellín: Trayectorias analiticas y poéticas. Medellín: Museo de la Memoria.

Pachón, X. (2009). La infancia perdida en Colombia: Los menores en la guerra. Working Paper Series, (15), recuperado de https://is.gd/E2xVYG

Para avanzar en la salida de niños, niñas y adolescentes de las FARC-EP se requiere compromiso de Gobierno y FARC-EP (2017). Radio Macondo, s. p.

Ruiz, S. (2002). Impactos psicosociales de la participación de niñ@s y jóvenes en el conflicto armado. En A. Bello y S. Ruiz (eds.), Conflicto armado, niñez y juventud: una perspectiva psicosocial. Bogotá: Universidad Nacional de Colombia y Fundación Dos Mundos. 
Sánchez-Queija, I., Oliva, A. y Parra, A. (2006). Empatía y conducta prosocial durante la adolescencia. Revista de Psicología Social, 21(3), 259-271.

Springer, N. (2012). Como corderos entre lobos: Del uso y reclutamiento de niñas, niños y adolescentes en el marco del conflicto armado y la criminalidad en Colombia. Bogotá: Springer Consultig Services. Recuperado de https://is.gd/9yas05

Unicef (2012). La niñez colombiana en cifras. Bogotá: Unicef. Recuperado de https://is.gd/9yas05

Vélez, M. (1999). Los hijos de la gran diosa: Psicología analítica, mito y violencia. Medellín: Universidad de Antioquia.

\section{Bibliografía complementaria}

Asesinatos de líderes sociales: Difieren las cifras, coinciden los contextos (18 de marzo de 2017). Verdad Abierta. Recuperado de https://is.gd/moSUPH

Campbell, J. (1997) El héroe de las mil caras: Psicoanálisis del mito. Ciudad de México: Fondo de Cultura Económica.

Castro, G. (1976). Colombia amarga. Bogotá: Carlos Valencia Editores.

Guattari, F. (1996). Las tres ecologías. Madrid: Pre-Textos.

Los niños "pisa suave", la escalofriante técnica de las Farc (24 de junio de 2012). Semana, recuperado de https://is.gd/26Q5Om

Marín, J. (2010). Revisión teórica respecto a las conductas prosociales: Análisis para una reflexión. Psicogente, 13(24), 369-388.

Ruiz, J. y Vélez, B. (2004). Fronteras invisibles de exclusión y de violencia. Medellín: Universidad de Antioquia.

Saavedra, L. (1990). Antropología de la violencia: Del azadón al gatillo. Bogotá: Fundayudas.

Salazar, A. (1991). No nacimos pa'semilla. Bogotá: Centro de Investigación y Educación Popular. 


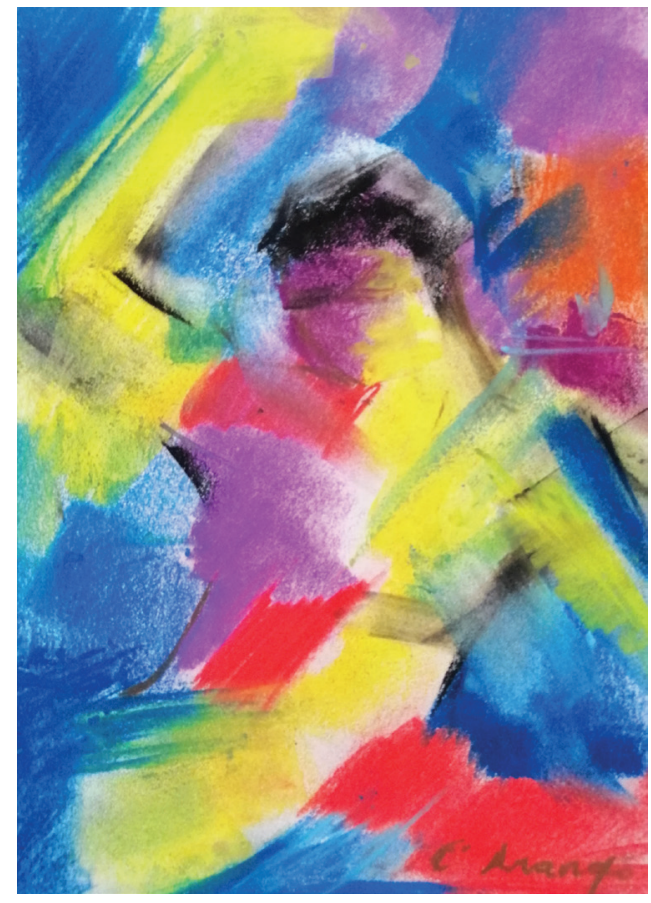

Pues yo creo que un niño tiene derecho al estudio, el primero, y el más fundamental; derecho a la salud; el niño también tiene derecho a la opinión, el niño también tiene derecho a divertirse y a ser niño; porque son niños, él también tiene derecho a ser, el niño es libre; como uno, él juega, salta, callejea, tiene derecho a ser feliz, a ver televisión; ellos también tienen derecho a lo que uno quiere, a lo que a uno le gusta, ellos también tienen derecho.

Madre de familia Hogar Infantil Fundehi, barrio El Arroyo, Cazucá, Soacha, 2017 


\section{Tema 10. El niño, sujeto de decisiones, de derechos y talentos}

\section{Presentación}

Es viable dentro del trabajo humanista pensar en los actores de interacción o de la intervención social. Siempre hay personas calificadas o expertos que trabajan con los educadores, con los padres de familia y con los niños para superar deficiencias, problemas, necesidades, síntomas y otra serie de dificultades, pero a la vez es necesario pensar que esa misma relación se da en la dimensión positiva del niño como sujeto, ya que es un ser lleno de posibilidades y de oportunidades para su propio desarrollo, y por lo tanto hay que aprender a escucharlo y a respetar sus gustos y decisiones.

\section{Propósito (objetivo)}

Precisar entre los docentes y padres de familia la dialéctica existente entre las dificultades del menor y sus potencialidades individuales y sociales, su capacidad de elegir y tomar decisiones de acuerdo con su edad y entorno (inteligencias múltiples) como medio para promover su autonomía e identidad personal. 